\section{SMARTPHONE APP FOR LOCUMS}

Locum Log is the first iPhone application for locum professionals to log a work diary and collate data for preparation of annual tax returns.

The app can be customised to accumulate everyday figures such as the number of UDAs/daily rate, fee per UDA and lab fees. Other expenses like parking and mileage can also be collected for the end of year accounts.

Dentists can benefit from the app by emailing locum agencies/employers availability and holiday plans. The work diary works the same as any smartphone calendar and can be a replacement for your native calendar.

Locum Log is also practical for locum dental nurses where fields such as rate per hour and hours per day can be calculated in the reports section of the app.

Not everyone feels safe with documenting sensitive data in such an open setting. This is where the developers of the app have introduced two security measures: firstly a pass code login to enable only the user to have access, and secondly non-web based activity ie storage that is native to the phone itself and avoids any cloud computing action.

Other features of the app include documenting pending payments,

\section{AVOID HEALTH AND SAFETY FINES}

Health and safety provider Helmsman Safety Services has launched a new free-of-charge online resource centre for their dentistry clients to enable them to keep all of their documentation in one easy to access place. In addition they are also offering a free e-booklet called 12 top health et safety tips for all directors and office managers.

In 2009-2010 there were 1,024 prosecutions for breaches of health and safety resulting in an average fine of $£ 13,393$ per breach.

Helmsman Safety Services offers

a 'Safe and Sure' annual contract to ensure dental practices are fully compliant with all health and safety regulations. Their new online resource centre is another way they can help practices deal with health and safety compliance in less time. Reader response number 55

\title{
HIGHLY EFFECTIVE TREATMENT POWDER
}

OSspray, from the Industrial Design Consultancy (IDC), is a successful supplier of dental biomaterials, including powders for polishing and regenerating tooth structure. One of their latest products, Sylc, is used to polish teeth while providing a protective enamel-like layer over the surface of the teeth. Sylc is a highly effective dental treatment powder which forms a mineral deposition as it is delivered through dental airpolisher equipment during treatment. Traditional air polishing equipment can result in powder overspray which the dentist has to clean up after each procedure; additionally the air polishing tip is a disposable item and has to be replaced frequently.

To help promote the acceptance of Sylc in the dental practice, OSspray decided to develop their own hardwearing delivery devices, which also

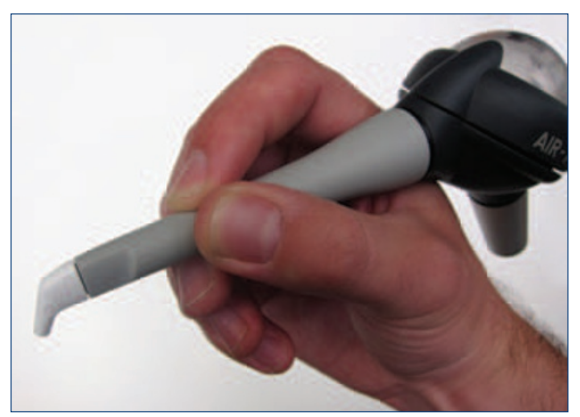

improves the access whilst in use and improves the patient's experience whilst being treated.

The new products enable two dental heads to use a common, high wearresistant ceramic nozzle and have improved ergonomics and aesthetics for better handling by dental professionals. The spray pattern of the dental powder is also enhanced to give a more focused delivery whilst reducing unwanted overspray.

Reader response number 56

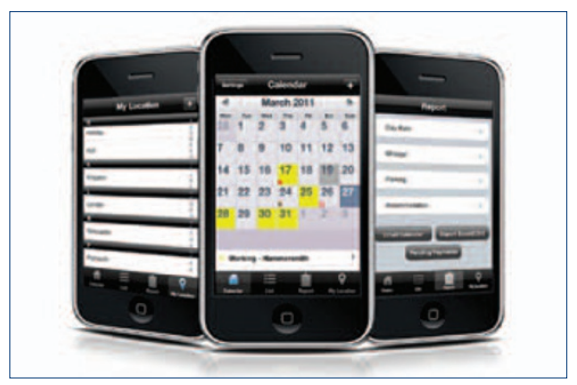

saving locations where one has worked and exporting files in Excel spreadsheet format to accountants.

Although currently only available to iPhone users, an Android version is being developed for launch next year. Reader response number 54

\section{INTUITIVE, EFFICIENT, ENHANCED}

NSK recently asked over 50 users of their VarioSurg ultrasonic surgical system why they used the system and what practical benefits it delivers.

VarioSurg users sited numerous benefits including the bright LED handpiece, which illuminates the operating field very clearly and, unlike some other machines, does not get hot with prolonged usage. Users also appreciated the efficient, gentle bone cutting delivered by the VarioSurg in comparison to drills, as the patient experiences much less pain and swelling in the post-op period, and that the incidence of complications are very low. Additionally users said the display was intuitive to use and very easy to navigate during surgery.

Users stated that the NSK

VarioSurg delivers strong, precise cutting power and an ultrasonic approach to surgery that reduces heat generation and minimises osteonecrosis. This is enhanced by TiN (Titanium Nitride) coated bone cutting tips, increasing cutting efficiency and leaving a sharp surface that aids bone formation.

The NSK VarioSurg and most of the NSK product range is available to clinicians on a 'try before you buy' basis.

Reader response number 57 